Jurnal Elektro Luceat [Juli] [2020]

\title{
PENERAPAN METODE LEARNING VECTOR QUANTIZATION UNTUK IDENTIFIKASI PENYAKIT PADI BERDASARKAN BENTUK BERCAK DAUN
}

\author{
Ery Murniyasih $^{1}$, Luluk Suryani ${ }^{2}$ \\ ${ }^{1}$ Politeknik Saint Paul Sorong \\ ${ }^{2}$ Politeknik Saint Paul Sorong \\ 1ery murniyasih@poltekstpaul.ac.id, ${ }^{2}$ Iuluk suryani@poltekstpaul.ac.id
}

\begin{abstract}
Abstrak
Penelitian ini bertujuan : (1). Membuat suatu aplikasi untuk identifikasi jenis penyakit pada tanaman padi berdasarkan bentuk bercak daun padi.;(2). Menerapkan metode Learning Vector Quantization ( $L V Q)$ pada identifikasi penyakit tanaman padi. Pada tahapan learning dan testing pada LVQ citra diproses menjadi Grayscale, Thresholding, dan segmentasi. Di tahap pelatihan, metode LVQ digunakan untuk menentukan bobot, target error, max epoch, dan laju pelatihan (Learning rate). Data yang dijadikan sebagai input adalah citra identifikasi jenis penyakit tanaman padi berdasarkan bentuk bercak daun padi yaitu dengan ukuran piksel $95 \times 35$ dan berekstensi BITMAP (.bmp). Standar keberhasilan sistem identifikasi ini adalah menghitung nilai Termination Error Rate dan tingkat keakuratan dalam identifikasi bentuk bercak daun. Dari simulasi ini diperoleh struktur Jaringan Syaraf Tiruan dengan jumlah nilai learning rate 0,02 dan jumlah epoch sebesar 5 kali. Sistem yang terbentuk mampu mengenali citra yang berisi bentuk bercak daun yang digunakan sebagai bobot dengan nilai keakuratan optimum yaitu $73,33 \%$ dengan komposisi penyakit bercak coklat (BC) $20 \%$, Blast $20 \%$ dan cercak cercospora 33,33\%.
\end{abstract}

\section{Kata kunci : identifikasi, Learning Vector Quantization (LVQ), penyakit, padi.}

\begin{abstract}
This research aims: (1). Make an application to identify types of diseases in rice plants based on the form of rice leaf spots; (2). Apply the Learning Vector Quantization (LVQ) method to the identification of rice plant diseases. In the learning and testing stages of LVQ the image is processed into Grayscale, Thresholding, and segmentation. At the training stage, the LVQ method is used to determine weights, target errors, max epochs, and training rates. The data used as input is an image of the identification of types of diseases of rice plants based on the shape of rice leaf spots with a pixel size of $95 \times 35$ and with the BITMAP extension (.bmp). The standard of success of this identification system is to calculate the value of the Termination Error Rate and the level of accuracy in the identification of leaf spot forms. From this simulation an artificial neural network structure was obtained with a learning rate value of 0.02 and an epoch number of 5 times. The system formed is able to recognize images containing leaf spot forms used as weights with an optimum accuracy value of $73.33 \%$ with a composition of brown spot disease (BC) $20 \%$, Blast $20 \%$ and cercospora blotches $33.33 \%$.
\end{abstract}

Keywords: identification, Learning Vector Quantization (LVQ), diseases, rice.

\section{PENDAHULUAN}

Padi merupakan salah satu tanaman budidaya terpenting dalam peradaban. Meskipun mengacu pada jenis tanaman budidaya, padi juga mengacu pada beberapa jenis dari marga (genus) yang sama, yang biasa disebut sebagai padi liar. Padi diduga berasal dari India atau Indocina dan masuk ke Indonesia dibawa oleh nenek moyang yang migrasi dari daratan Asia sekitar 1500 SM.

PENERAPAN METODE LEARNING VECTOR QUANTIZATION UNTUK IDENTIFIKASI PENYAKIT PADI BERDASARKAN BENTUK BERCAK DAUN 
Jurnal Elektro Luceat [Juli $]$ [2020]

Produksi padi dunia menempati urutan ketiga dari semua serealia, setelah jagung dan gandum. Namun demikian, padi merupakan sumber karbohidrat utama bagi mayoritas penduduk dunia.[1]

Untuk menjaga kualitas tanaman padi dalam hal produksi, petani mesti dikenalkan dengan teknologi guna melihat pengaruh pertumbuhan padi, hal ini difokuskan pada penyakit yang menyerang tanaman padi. Berdasarkan hal tersebut, sebagai kontribusi keilmuan dan teknologi maka dibuat sebuah aplikasi untuk mengenalkan kepada para petani melalui Dinas Pertanian Kabupaten Sorong dalam mengidentifikasi penyakit padi berdasarkan morfologi bercak daun padi.

Pada penelitian ini metode yang digunakan untuk melakukan pengelompokan pada penyakit padi berdasarkan bercak daun padi adalah metode Learning Vector Quantization $(L V Q)$. LVQ adalah metode pembelajaran pada lapisan kompetitif yang terawasi. Suatu lapisan kompetitif akan secara otomatis belajar untuk mengklasifikasikan vektor-vektor input. Kelas - kelas yang didapatkan sebagai hasil dari lapisan kompetitif ini hanya tergantung pada jarak antara vektor-vektor input. Jika 2 vektor input mendekati sama, maka lapisan kompetitif akan meletakkan kedua vektor input tersebut kedalam kelas yang sama.[2]

\section{DASAR TEORI}

\subsection{Metode Learning Vector Quantization (LVQ)}

Learning Vector Quantization (LVQ) merupakan salah satu contoh dari metode jaringan syaraf tiruan, hampir sama dengan Self Organising Maps (SOM) atau kohene berdasarkan cara kerjanya. Hanya saja pada LVQ terlebih dahulu menetapkan target output yang akan dicapai sedangkan pada kohene tidak demikian. LVQ dapat diterapkan pada Identifikasi pola, klasifikasi dengan banyak kelas seperti Identifikasi suara, pengolahan image atau klasifikasi pelanggan. Sebagai bagian dari metode terawasi, LVQ biasanya dikenal dengan pengklasifikasian output target untuk beberapa pola input yang tersedia. Dan setiap output unit memiliki kelas tersedia yang diwakili.[3]

\subsection{Skala Keabuan (Grayscale)}

Grayscale disebut juga dengan citra 8-bit karena memiliki 28 (256) kemungkinan nilai pada masing-masing pixel-nya. Nilai tersebut dimulai dari nol untuk warna hitam dan 255 untuk warna putih.[4]

Agar dapat merubah citra berwarna yang mempunyai nilai matriks, masing- masing red(r), green (g), dan blue (b) menjadi citra grayscale dengan nilai s, kita dapat melakukan konversi dengan mengambil rata- rata nilai $r, g$, dan $b$.

sehingga dapat dirumuskan menjadi :

$$
s=\frac{\mathrm{r}+\mathrm{g}+\mathrm{b}}{3} \text {. }
$$

\subsection{Konversi Gambar True Color ke Grayscale}

Untuk mengubah gambar true color ke grayscale kita membutuhkan nilai $R, G, B$ dari gambar true color . Nilai pixel dari gambar grayscale sendiri merupakan gabungan dari $30 \%$ dari nilai $\mathrm{R}$ ditambah $59 \%$ dari nilai $\mathrm{G}$ di tambah $11 \%$ dari nilai B.[5]

\subsection{Thresholding}

Image thresholding adalah sebuah metode yang digunakan untuk memisahkan objek dengan background. Image akan dibagi menjadi dua bagian dengan suatu batasan ambang "T" 
ditetapkan sebagai pemisahnya. Masing-masing pixel $(x, y)$ pada image dengan nilai $f(x, y) \geq T$ akan bernilai 0 (putih).[6]

$$
\begin{aligned}
& \mathrm{g}(\mathrm{x}, \mathrm{y})=1 \text { if } f(\mathrm{x}, \mathrm{y}) \geq \mathrm{T} \\
& \mathrm{g}(\mathrm{x}, \mathrm{y})=0 \text { if } f(\mathrm{x}, \mathrm{y})<\mathrm{T} \ldots \ldots \ldots \ldots \ldots \ldots \ldots \ldots \ldots \ldots \ldots \ldots \ldots \ldots \ldots \ldots \ldots \ldots \ldots \ldots \ldots \ldots \ldots
\end{aligned}
$$

\subsection{Learning Rate}

Learning rate merupakan sebuah konstanta yang dapat dipakai oleh algoritma pembelajaran. Learning rate harus sebuah bilangan positif kurang dari satu dan diberi simbol $\alpha$ (alpha). Secara umum dengan memberikan learning rate nilai yang besar maka akan mempercepat pembelajaran. Permasalahan learning rate yang terlalu besar dapat diatasi dengan cara mengurangi learning rate tersebut pada setiap iterasinya (epoch) bersamaan dengan proses pembelajaran.[7]

\subsection{Pembobot (Weight)}

Memori keseluruhan dari LVQ neuron network disimpan pada weight conection antara input dan output layar. Weight diatur disetiap iterasi (epoch). Sebuah iterasi muncul saat training data diberikan pada LVQ neuron network dan weigth diatur berdasarkan hasil jarak (Euclidian distance) pelatihan data. Weight matriks yang akan digunakan merupakan weight terbaik yang akan dihasilkan pada setiap iterasi.[8]

Metode yang digunakan untuk menghitung perubahan weight tersebut adalah sebagai berikut:

$$
\begin{aligned}
& \mathrm{W}_{\text {new }}=\mathrm{W}_{\text {old }}+\alpha\left[\mathrm{x}-\mathrm{W}_{\text {old }}\right] . \\
& \mathrm{W}_{\text {new }}=\mathrm{W}_{\text {old }}-\alpha\left[\mathrm{x}-\mathrm{W}_{\text {old }}\right] .
\end{aligned}
$$

\section{PEMBAHASAN}

\subsection{Identifikasi dan Pengumpulan Data}

Data untuk mengenali jenis penyakit padi berdasarkan bentuk bercak daun padi diperoleh dari 3 jenis penyakit padi yang berbeda, kemudian diambil gambar untuk menentukan gambar yang akan diperoleh dan dipakai pada pengujian program. Jumlah sampel gambar yang diambil sebanyak 45 sampel gambar bercak daun padi dari 3 jenis penyakit yang berbeda. Berikut adalah

\begin{tabular}{|c|c|c|c|c|}
\hline No & Penyakit & Penyebab & Gejala & Bentuk \\
\hline 1. & $\begin{array}{l}\text { Bercak cokelat } \\
\text { (Brown Spot) }\end{array}$ & $\begin{array}{l}\text { Jamur } \\
\text { Helminthosporium } \\
\text { oryzae }\end{array}$ & $\begin{array}{l}\text { Bercak daun memanjang } \\
\text { (oval), bagian tengah } \\
\text { berwarna kuning pucat dan } \\
\text { kelabu, terkadang dikelilingi } \\
\text { halo }\end{array}$ & \\
\hline 2. & Blast & $\begin{array}{l}\text { Jamur } \\
\text { oryzae }\end{array}$ & $\begin{array}{l}\text { Bentuk khas dari blas daun } \\
\text { adalah bercak belah ketupat } \\
\text { dengan kedua ujung yang } \\
\text { runcing. }\end{array}$ & \\
\hline 3. & $\begin{array}{l}\text { Bercak } \\
\text { Cercospora } \\
\text { (Narrow Brown } \\
\text { Leaf Spot) }\end{array}$ & $\begin{array}{ll}\text { Jamur } & \text { Cercospora } \\
\text { oryzae } & \end{array}$ & $\begin{array}{l}\text { Menyerang daun dan pelepah. } \\
\text { Ada gari-garis atau bercak- } \\
\text { bercak sempit memanjang } \\
\text { sepanjang } 2-10 \mathrm{~mm} \text {. }\end{array}$ & \\
\hline
\end{tabular}
data tentang identifikasi jenis penyakit padi dari pengambilan gambar dimana data tersebut diambil dari Dinas Pertanian Kabupaten Sorong :

Tabel 1. Bentuk Bercak Daun Padi dan Jenis Penyakit Padi

\subsection{Perancangan Sistem}

Berikut adalah flowchart sistem untuk proses pelatihan dan pengujian pada Jaringan Syaraf Tiruan dengan menggunakan metode Learning Vector Quantization (LVQ) 
a. Flowchart sistem untuk proses pelatihan:

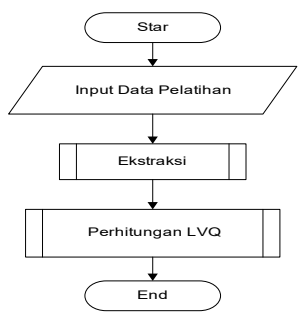

Gambar 1. Flowchat Sistem Proses Pelatihan (Training)

b. Flowchart sistem untuk proses pengujian gambar:

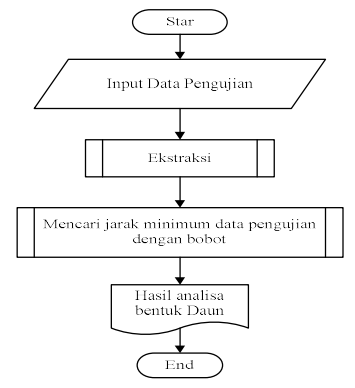

Gambar 2. Flowchart Sistem Proses Pengujian(Testing)

\subsection{Data Gambar Inputan}

Data input yang digunakan merupakan data gambar pola bentuk bercak daun padi. Data input dibedakan menjadi dua yaitu : data gambar untuk tahap pelatihan (training) dan data gambar untuk tahap pengujian (testing). Data gambar untuk tahap pengujian dan pelatihan mengunakan ukuran pixel gambar 35 x 95 pixel dengan ekstensi bmp, data pelatihan (Training) sejumlah 45 data, data pengujian (Testing) sejumlah 20 data.

\subsection{Set Parameter Jaringan Syaraf Tiruan}

Nilai konstanta Learning rate yang digunakan adalah 0,02.Proses iterasi dibatasi 5 iterasi disesuaikan dengan percobaan yang telah dilakukan dan penambahan jumlah iterasi tidak mempengaruhi keberhasilan dalam mengenali data gambar pola bentuk bercak daun padi dalam proses testing.

Tabel 2. Percobaan Pencarian Nilai Parameter Learning Rate dan Maksimum Iterasi.

\begin{tabular}{|c|c|c|c|c|c|c|}
\hline \multicolumn{7}{|c|}{ Data Dikenali } \\
\hline \multirow{2}{*}{$\begin{array}{l}\text { Iterasi } \\
\text { (Epoch) }\end{array}$} & \multicolumn{5}{|c|}{ Learning Rate $(\alpha)$} & \multirow{2}{*}{ Data Testing } \\
\hline & 0.01 & 0.02 & 0.03 & 0.04 & 0.5 & \\
\hline 1 & 4 & 1 & 4 & 3 & 2 & 15 \\
\hline 2 & 3 & 1 & 3 & 2 & 3 & 15 \\
\hline 3 & 1 & 4 & 2 & 6 & 9 & 15 \\
\hline 4 & 3 & 5 & 6 & 7 & 10 & 15 \\
\hline 5 & 1 & 11 & 10 & 7 & 0 & 15 \\
\hline
\end{tabular}




\subsection{Ekstraksi}

Proses ekstraksi terdapat proses grayscaling image lalu image dibuat hitam putih dengan thresholding tujuannya untuk memisahkan object daun padi dengan background. Proses ini dapat mengurangi pencahayaan image sehingga identifikasi warna hitam putih terlihat dengan jelas. Metode yang digunakan dalam perancangan sistem ini dengan membagi nilai maksimum dari suatu image yaitu : 255 dan 156 sehingga pada saat nilai lebih besar dari 156 maka akan diidentifikasi sebagai warna hitam, apabila hasil pembagian lebih kecil dari 156 maka akan didefinisikan sebagai warna putih. Selanjutnya hasil identifikasi dirubah menjadi nilai binary pixel yaitu hitam $=0$ dan putih $=1$, nilai tersebut yang akan dijadikan inputan dari masing-masing neuron yang dibuat dalam metode LVQ untuk training atau testing dari image.

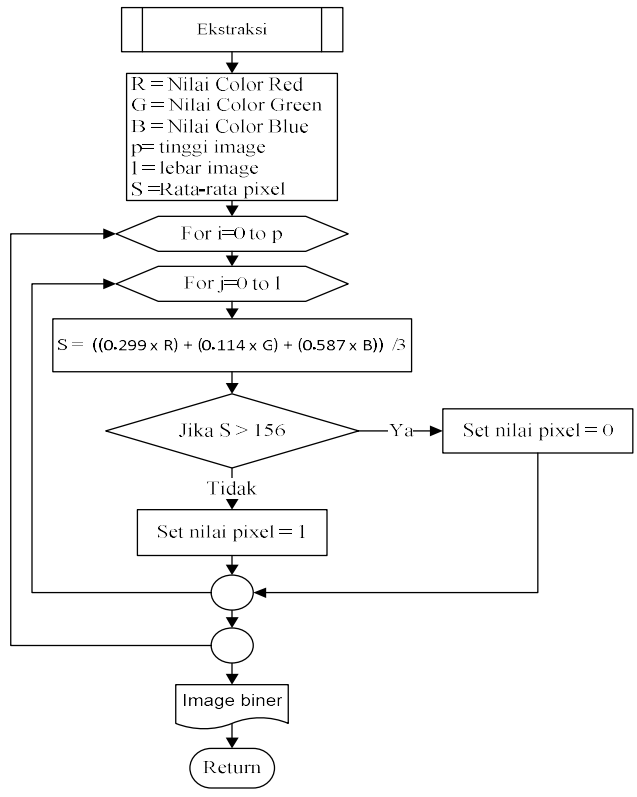

Gambar 3. Flowchart ekstraksi gambar

\subsection{Implementasi Sistem}

\subsubsection{Tampilan Menu Utama}

Pada menu utama adalah menu awal pada saat program ini dijalankan. Menu utama terdiri dari 3 panel menu yaitu Menu, Learning, Testing, About. Pada panel Menu terdiri dari 3 sub menu yaitu Login, Logout dan Exit.

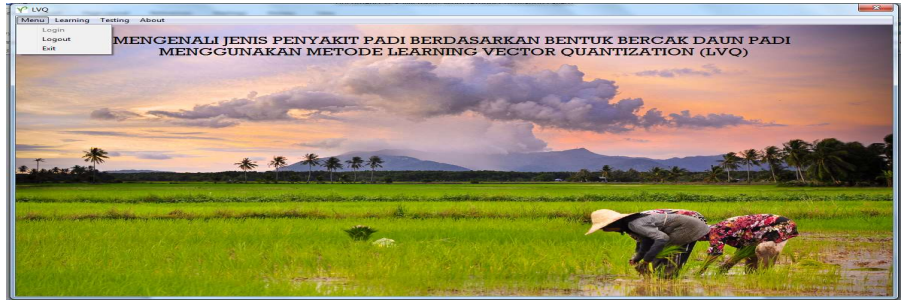

Gambar 4. Tampilan Menu Utama

\subsubsection{Tampilan Menu Training}

Menu training data merupakan menu dimana data akan digunakan sebagai pola awal pengenalan. Pola-pola masukkan akan membuat jaringan berlatih secara terus-menerus. Semakin sering jaringan berlatih maka kemungkinan jaringan akan mengenali pola baru akan semakin besar. 
JEC Vol. 6 No. 1

Jurnal Elektro Luceat [Juli $]$ [2020]

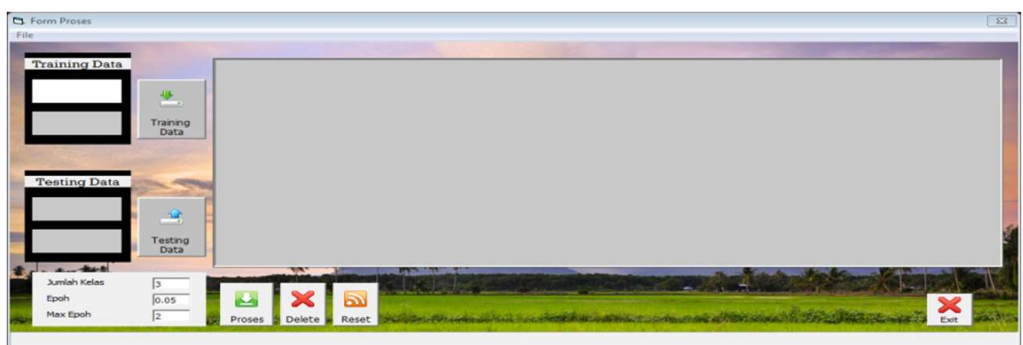

Gambar 5. Menu Learning

\subsubsection{Tampilan Testing Pengenalan Jenis Penyakit}

Setelah proses Learning selesai maka proses selanjutnya adalah proses Testing dan identifikasi image penyakit padi yang telah di-load proses ini juga terdapat proses load image seperti pada proses-proses sebelumnya.

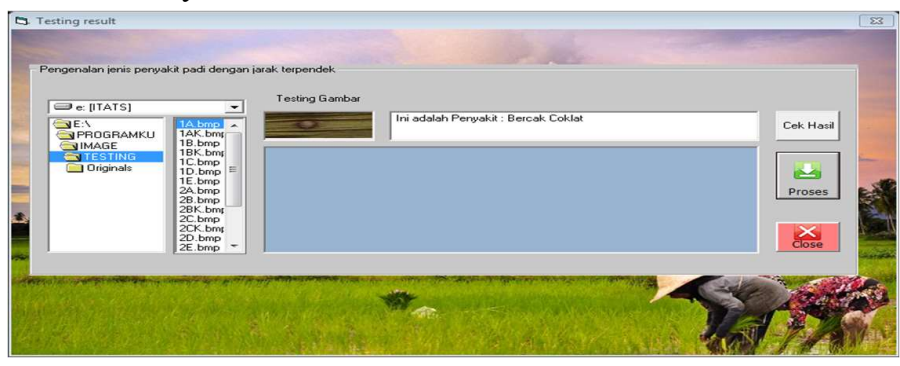

Gambar 6. Pengenalan Jenis Penyakit

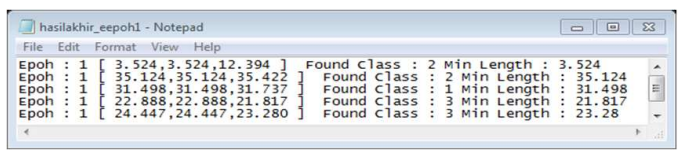

Gambar 7. Hasil Testing Notepad

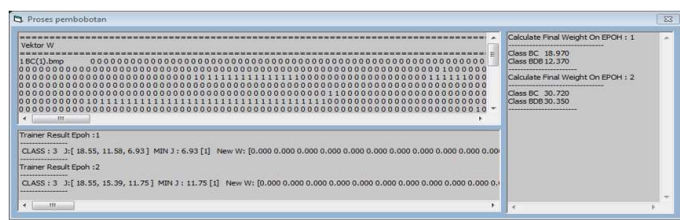

Gambar 8. Tampilan Proses Pembobotan

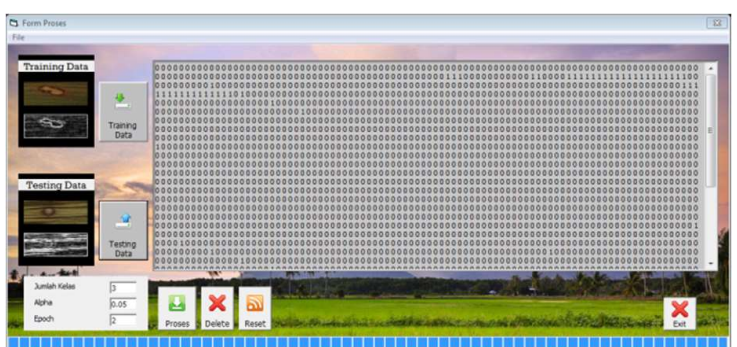

Gambar 9. Proses Training dan Testing Selesai

\subsection{Analisis Percobaan}

Menamakan lima jenis penyakit padi yaitu : dimana Angka 1A, 1AK, 1BK, 1C, 1D, 1E menunjukkan kelas bercak coklat, angka 2AK, 2B, 2C, 2CK, 2D, 2E menunjukkan kelas bercak cercospora, angka 3A, 3AK, 3B, 3C, 3D, 3E menunjukkan kelas blast . Pengujian dilakukan untuk menentukan seberapa besar tingkat keberhasilan dari sistem yang dibuat ini. 
JEC Vol. 6 No. 1

Jurnal Elektro Luceat [Juli $]$ [2020]

Tabel 3. Hasil Percobaan

\begin{tabular}{|c|c|c|c|c|c|c|}
\hline No & $\begin{array}{l}\text { Bentuk } \\
\text { Bercak }\end{array}$ & $\begin{array}{c}\text { Jenis Penyakit } \\
\text { Padi }\end{array}$ & Epoch & $\begin{array}{l}\text { Alpha } \\
(\alpha)\end{array}$ & Identifikasi & $\begin{array}{l}\text { Keakuratan } \\
\text { Identifikasi }\end{array}$ \\
\hline 1 & 8 & Bercak Coklat & 5 & 0.02 & Dikenali & \multirow{20}{*}{$75 \%$} \\
\hline 2 & 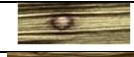 & Bercak Coklat & 5 & 0.02 & Dikenali & \\
\hline 3 & & Bercak Coklat & 5 & 0.02 & Dikenali & \\
\hline 4 & & Bercak Coklat & 5 & 0.02 & Dikenali & \\
\hline 5 & 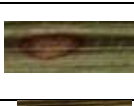 & Bercak Coklat & 5 & 0.02 & $\begin{array}{c}\text { Tidak } \\
\text { Dikenali }\end{array}$ & \\
\hline 6 & 0 & Bercak Coklat & 5 & 0.02 & Dikenali & \\
\hline 7 & & Bercak Coklat & 5 & 0.02 & $\begin{array}{c}\text { Tidak } \\
\text { Dikenali }\end{array}$ & \\
\hline 8 & & $\begin{array}{c}\text { Bercak } \\
\text { Cercospora }\end{array}$ & 5 & 0.02 & Dikenali & \\
\hline 9 & & $\begin{array}{c}\text { Bercak } \\
\text { Cercospora }\end{array}$ & 5 & 0.02 & Dikenali & \\
\hline 10 & $=$ & $\begin{array}{c}\text { Bercak } \\
\text { Cercospora }\end{array}$ & 5 & 0.02 & Dikenali & \\
\hline 11 & & $\begin{array}{c}\text { Bercak } \\
\text { Cercospora }\end{array}$ & 5 & 0.02 & Dikenali & \\
\hline 12 & $=$ & $\begin{array}{c}\text { Bercak } \\
\text { Cercospora }\end{array}$ & 5 & 0.02 & Dikenali & \\
\hline 13 & & $\begin{array}{c}\text { Bercak } \\
\text { Cercospora }\end{array}$ & 5 & 0.02 & Dikenali & \\
\hline 14 & & $\begin{array}{c}\text { Bercak } \\
\text { Cercospora }\end{array}$ & 5 & 0.02 & Dikenali & \\
\hline 15 & & Blast & 5 & 0.02 & $\begin{array}{c}\text { Tidak } \\
\text { Dikenali }\end{array}$ & \\
\hline 16 & $\infty$ & Blast & 5 & 0.02 & $\begin{array}{c}\text { Tidak } \\
\text { Dikenali }\end{array}$ & \\
\hline 17 & $E$ & Blast & 5 & 0.02 & Dikenali & \\
\hline 18 & & Blast & 5 & 0.02 & $\begin{array}{c}\text { Tidak } \\
\text { Dikenali }\end{array}$ & \\
\hline 19 & 8 & Blast & 5 & 0.02 & Dikenali & \\
\hline 20 & 25 & Blast & 5 & 0.02 & Dikenali & \\
\hline
\end{tabular}

Dari hasil pengujian menunjukan dengan persentasi identifikasi yang menyatakan perbandingan banyaknya input yang dikenali dari keseluruhan input yang diuji. Tabel 3 menunjukkan bahwa 15 input image bercak daun padi dikenali dari 20 input image bercak daun padi.

Rumus persentase identifikasi adalah sebagai berikut :

$$
\begin{aligned}
\text { Identifikasi }(\%) & =\left(\frac{\text { banyak data yang dikenali }}{\text { jumlah data uji }}\right) \times 100 \% \\
= & \left(\frac{15}{20}\right) \times 100 \%=75 \%
\end{aligned}
$$


JEC Vol. 6 No. 1

Jurnal Elektro Luceat [Juli] [2020]

\section{KESIMPULAN DAN SARAN}

\subsection{Kesimpulan}

Kesimpulan penerapan metode Learning Vector Quantization pada identifikasi penyakit tanaman padi adalah sebagai berikut:

- Jaringan LVQ yang terdiri dari layer input, layer kompetitif dan layer output dapat digunakan untuk pengenalan pola/klasifikasi berdasarkan kedekatan jarak antar kelompok.

- Dalam percobaan yang telah dilakukan dengan menggunakan metode learning vector quantization dengan alpha $=0.02$, toleransi kesalahan $(E p s)=0.001$, pengurangan alpha $=$ 0.5 , hasil iterasi maximum 5 dan menghasilkan sistem yang mempunyai tingkat akurasi sebesar (75\%) dan mempunyai tingkat error (25\%) dalam mengenali jenis penyakit padi berdasarkan bentuk bercak daun padi.

\subsection{Saran}

Penelitian masih banyak membutuhkan pengembangan untuk meningkatkan persentase keberhasilan dimana sistem diharapkan lebih cepat dalam melakukan proses penyeleksian,per dicoba menggunakan metode ekstraksi ciri yang lain dan kemungkinan untuk menggunakan pengurangan alpha yang lain. Selain itu, semakin banyak data untuk learning akan mempengaruhi tingkat keberhasilan program dalam mengenali pola inputan baru.

\section{DAFTAR PUSTAKA}

[1] Reflis, M. Nurung, and J. D. Pratiwi, "Motivasi Petani Dalam Mempertahankan Sistem Tradisional Pada Usahatani Padi Sawah Di Desa Parbaju Julu Kabupaten Tapanuli Utara Propinsi Sumatera Utara," J. AGRISEP, vol. 10, no. 1, pp. 51-62, 2011, doi: 10.31186/jagrisep.10.1.51-62.

[2] R. Meliawati, O. Soesanto, and D. Kartini, "Penerapan Metode Learning Vector Quantization (LVQ) Pada Prediksi Jurusan Di SMA PGRI 1 Banjarbaru," Kumpul. J. Ilmu Komput., vol. 04, no. 01, pp. 11-20, 2016.

[3] I. Singh, "Face Recognition through Multilayer Perceptron ( MLP ) and Learning Vector Quantization ( LVQ )," vol. 1, no. 10, pp. 87-90, 2012.

[4] F. Muwardi and A. Fadlil, "Sistem Pengenalan Bunga Berbasis Pengolahan Citra dan Pengklasifikasi Jarak," J. Ilm. Tek. Elektro Komput. dan Inform., vol. 3, no. 2, p. 124, 2018, doi: $10.26555 /$ jiteki.v3i2.7470.

[5] R. Santi, "Mengubah Citra Berwarna Menjadi Gray-Scale dan Citra Biner," None, vol. 16, no. 1, p. 243035, 2011.

[6] I. Setiawan, W. Dewanta, H. A. Nugroho, and H. Supriyono, "Pengolah Citra Dengan Metode Thresholding Dengan Matlab R2014A," J. Media Infotama, vol. 15, no. 2, pp. 6570, 2019.

[7] U. Sudibyo, D. P. Kusumaningrum, E. H. Rachmawanto, and C. A. Sari, "Optimasi Algoritma Learning Vector Quantization (Lvq) Dalam Pengklasifikasian Citra Daging Sapi Dan Daging Babi Berbasis Glcm Dan Hsv," Simetris J. Tek. Mesin, Elektro dan Ilmu Komput., vol. 9, no. 1, pp. 1-10, 2018, doi: 10.24176/simet.v9i1.1943.

[8] H. Pujara and K. MVV, "Image Segmentation using Learning Vector Quantization of Artificial Neural Network," Int. J. Adv. Res. Artif. Intell., vol. 2, no. 7, pp. 51-55, 2013, doi: 10.14569/ijarai.2013.020708. 